\title{
Antibacterial Activity of Plastics Coated with Silver-Doped Organic-Inorganic Hybrid Coatings Prepared by Sol-Gel Processes
}

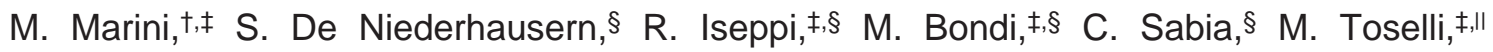 \\ and F. Pilati*,†, \\ Dipartimento di Ingegneria dei Materiali e dell'Ambiente, Via Vignolese, 905/A, and Dipartimento di \\ Scienze Biomediche, Via Campi, 213/ D, University of Modena and Reggio Emilia, 41100 -Modena, Italy, \\ Dipartimento di Chimica Applicata e Scienza dei Materiali, Alma Mater Studiorum, University of Bologna, \\ Viale Risorgimento, 2, 40136 -Bologna, Italy, and Consorzio Interuniversitario di Scienza e Tecnologia
} dei Materiali, Via Giusti, 9, 50121 - Firenze, Italy

Received July 24, 2006; Revised Manuscript Received January 22, 2007

\begin{abstract}
Silver-doped organic-inorganic hybrid coatings were prepared starting from tetraethoxysilane- and triethoxysilaneterminated poly(ethylene glycol)-block-polyethylene by the sol-gel process. They were applied as a thin layer $(0.6-1.1 \mu \mathrm{m})$ to polyethylene (PE) and poly(vinyl chloride) (PVC) films and the antibacterial activity of the coated films was tested against Gram-negative (Escherichia coli ATCC 25922) and Gram-positive (Staphylococcus aureus ATCC 6538) bacteria. The effect of several factors (such as organic-inorganic ratio, type of catalyst, time of post-curing, silver ion concentration, etc.) was investigated. Measurements at different contact times showed a rapid decrease of the viable count for both tested strains. The highest antibacterial activity [more than $6 \log$ reduction within $6 \mathrm{~h}$ starting from $10^{6}$ colony-forming units (cfu) $\mathrm{mL}^{-1}$ ] was obtained for samples with an organicinorganic weight ratio of 80:20 and $5 \mathrm{wt} \%$ silver salt with respect to the coating. For the coatings prepared by an acid-catalyzed process, a high level of permanence of the antibacterial activity of the coated films was demonstrated by repeatedly washing the samples in warm water or by immersion in physiological saline solution at $37{ }^{\circ} \mathrm{C}$ for 3 days. The release of silver ions per square meter of coating is very similar to that previously observed for polyamides filled with metallic silver nanoparticles; however, when compared on the basis of Ag content, the concentration of silver ions released from the coating is much higher than that released from $1 \mathrm{~mm}$ thick specimens of polyamide (PA) filled with silver nanoparticles. Transparency and good adhesion of the coating to PE and PVC plastic substrates without any previous surface treatment are further interesting features.
\end{abstract}

\section{Introduction}

Plastics, due to their low cost, good mechanical properties, and easy high-temperature processability, are widely used to prepare biomedical devices and food packaging. However, typically they do not have inherent antibacterial properties, an important feature in prevention of infection in humans by microorganisms like bacteria, molds, yeasts, viruses, etc., present in the living environment, for both biomedical and food packaging applications.

For this reason extensive research has been carried out in the last decades in order to investigate possible methods to prepare antibacterial plastics.

New plastic materials with inherent antibacterial properties can be made for this purpose by polymerization or copolymerization of new monomers ${ }^{1-4}$ or by chemical modification and/ or blending of polymers. ${ }^{5-8}$ However the development of new materials by use of new monomers often leads to unacceptable high costs and changes in the bulk properties, and sometimes

* Author to whom correspondence should be addressed. Phone: +39059-2056213. Fax: +39-059-2056243. E-mail: pilati.francesco@unimore.it.

$\dagger$ Dipartimento di Ingegneria dei Materiali e dell’Ambiente, University of Modena and Reggio Emilia.

$\doteqdot$ INSTM.

$\S$ Dipartimento di Scienze Biomediche, University of Modena and Reggio Emilia.

"University of Bologna. the obtained materials suffer from poor thermal stability, which limits their processability.

Thus the most frequently used approach to prepare antibacterial plastics is to include various organic or inorganic substances, such as tea extract, chitosan, copper, silver, zinc, etc., ${ }^{9-30}$ in polymer matrices.

Among the additives used to improve the antibacterial activity of plastics, those able to release silver ions have long been known to have strong bactericidal effects as well as a broad spectrum of antimicrobial activities. ${ }^{19-22}$ Several studies have been reported to explain the inhibitory effect of silver on bacteria, and it is generally believed that silver ions interact with proteins by reacting with the thiol groups of methionine or cysteine amino acids of the active site of the enzymes, leading to the inactivation of the proteins. In particular, Feng et al., ${ }^{20}$ while investigating the inhibition mechanism of silver ions on microorganisms, arrived at the conclusion that these ions affect the DNA replication capability, which in turn induces the inactivation of bacterial proteins. The inclusion in polymers of silver salts able to release $\mathrm{Ag}^{+}$is not an easy task due to poor miscibility of inorganic salts in plastics, difficulty in obtaining a fine dispersion, and poor diffusion of $\mathrm{Ag}^{+}$within hydrophobic nonpolar polymers.

For all these reasons, nanocrystalline metallic silver particles are commonly included in polymers during extrusion ${ }^{23-25}$ to obtain commercial antibacterial plastics able to release silver 
Scheme 1. Reactions Involved in the Sol-Gel Process

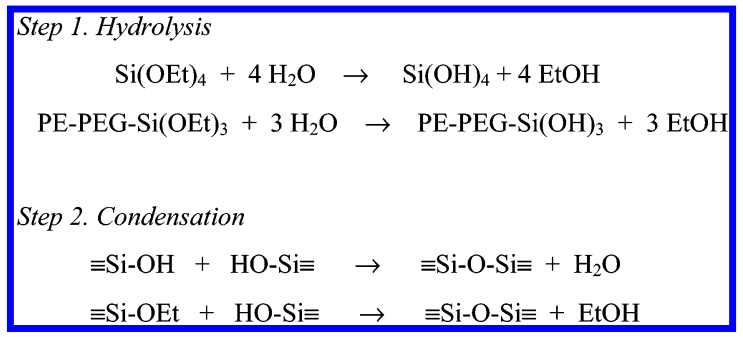

ions for a long period of time. ${ }^{24-30}$ However, this approach presents several drawbacks: most of the inner silver nanoparticles may not contribute to give any antibacterial effect at all; it is very difficult to obtain a homogeneous dispersion of silver nanoparticles, and therefore it is almost impossible to obtain transparent materials; the formation of $\mathrm{Ag}^{+}$requires water uptake, ${ }^{25}$ and therefore this approach cannot be extended to highly hydrophobic polymers; and, also importantly, the silver nanoparticles are very expensive. Attempts to improve the silver ion release have been done by using zeolites or other inorganic particles as a carrier for silver. ${ }^{25}$

When specific surface properties are required, another more preferable strategy is the use of functional coatings, which allow the surface properties of a given substrate to be modified while leaving the bulk properties unchanged. Of course, in order to meet the required functionality and permanence, good mechanical properties of the coating and good adhesion to the substrate are critical points.

In this view, different methods to generate silver ions onto only the surface of plastics have been proposed by using several deposition techniques such as vapor coating, ion implantation, sputtering, or electrochemical deposition from solution. ${ }^{29,31-36}$ However, these technologies have some drawbacks: they are quite expensive and not easily applicable to large and/or complex item geometries, the adhesion of the coating to the plastic substrate can be poor without previous surface treatments, and transparency could be lost.

Another possible approach to coating plastics is the preparation of organic-inorganic hybrid coatings by a sol-gel process. It seems particularly attractive because it presents several advantages such as high purity of the reactants and of the resulting products; mild processing conditions (low temperature, atmospheric pressure); possible control of connectivity and morphology by suitable choice of reactants, catalyst, and reaction conditions; easy application to any kind of substrate; transparency due to the nanosized organic and inorganic domains; and, particularly interesting for this study, easy inclusion of inorganic salts in the starting solution to obtain a homogeneous dispersion. Moreover, by a suitable choice of the organic-phase precursor (chemical nature and relative weight fraction) it should also be possible to adjust the mechanical properties of the coating, its morphology, and the adhesion of the coating to the plastic substrate. As a consequence, the diffusion rate of the included additives may in principle be controlled in order to prepare coatings able to release the trapped functional additives at the desired rate. Indeed, the possibility of preparing bioactive materials by using materials obtained by the sol-gel approach has been recently proposed. ${ }^{37-39}$

In this context we seek to develop antibacterial plastics by applying a functional organic-inorganic hybrid coating to traditional plastics such as polyethylene (PE) and poly(vinyl chloride ) (PVC). Some examples of antibacterial coatings have been reported for substrates such as metal and inorganic glasses $;{ }^{40-42}$ however, their application to plastic substrates often

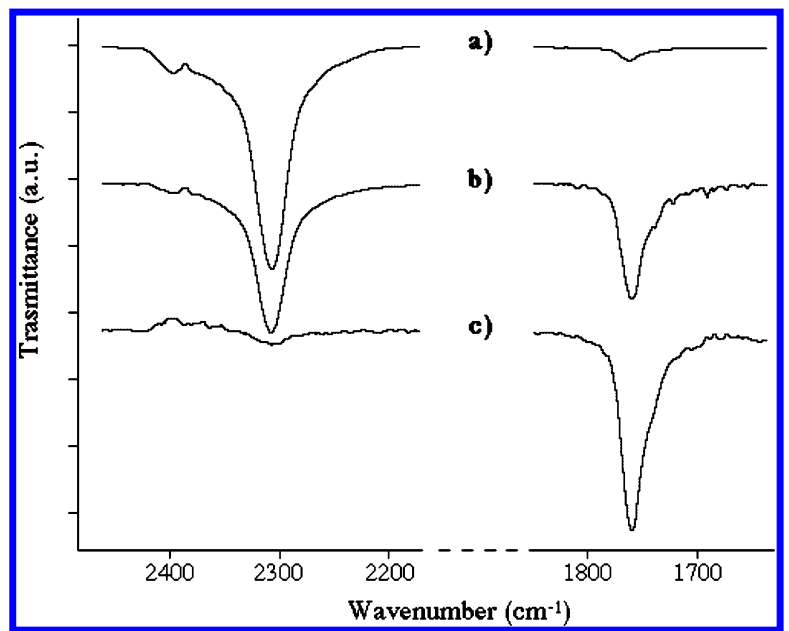

Figure 1. Synthesis of triethoxysilane-terminated PE-PEG copolymer. FT-IR spectra were recorded at different reaction times: (a) 0.2 , (b) 1 , and (c) $3 \mathrm{~h}$.

fails because of poor adhesion, and surface pretreatments such as corona discharge, oxidative chemical attack, and plasma treatment are required in most cases, in particular for polyolefins. ${ }^{43}$

In previous works ${ }^{44-47}$ it has been demonstrated that a suitable choice of the polymer for use in preparation of hybrid coatings can lead to good adhesion without any pretreatment of the plastic substrate.

Therefore, the main goal of this study was to demonstrate that the application of sol-gel coatings to widely used substrates such as PE and PVC is a possible approach to develop new functional biomaterials (as was recently reported for nitric oxide release $^{38}$ ). In an effort to improve the antibacterial activity of plastic medical devices and food packaging, we developed and studied silica-based organic-inorganic hybrid coatings including cheap inorganic salts (in particular, silver salts such as $\mathrm{AgNO}_{3}$ and $\mathrm{AgCl}$ ) instead of the expensive silver nanoparticles. Additional goals were to understand the role of some process variables, such as organic-inorganic ratio and type of catalyst and inorganic ions $\left(\mathrm{Ag}^{+}\right.$and $\left.\mathrm{Zn}^{2+}\right)$, and to study the effects of these coatings on different types of bacteria. Transparency preservation, good adhesion to the plastic substrates, and permanence of the antibacterial activity after a long time and several washes were further additional goals.

\section{Experimental Section}

2.1. Materials. Bubble-extruded low-density polyethylene (LDPE) thin films ( $50 \mu \mathrm{m}$ thick, supplied by Polimeri Europa S.P.A, Italy) and unplasticized PVC films $(150 \mu \mathrm{m}$ thick, supplied by Lucchesi S.P.A, Italy) were used, as received, as polymer substrates for hybrid coatings.

High-purity tetraethoxysilane (TEOS, Aldrich), 3-isocyanatopropyltriethoxysilane (ICPTES, Fluka), nitric acid at $65 \%$ concentration (Carlo Erba), $\mathrm{AgNO}_{3}$ (Fluka), $\mathrm{ZnCl}_{2}$ (Fluka), $\mathrm{AgCl}$ (Carlo Erba), ethanol (EtOH, Carlo Erba), tetrahydrofuran (Carlo Erba), polyethylene-blockpoly(ethylene glycol) (PE-PEG, 80/20 wt ratio, $\mathrm{M}_{\mathrm{n}} 2250$, Aldrich) were used as received without further purification.

Gram-negative (Escherichia coli ATCC 25922) and Gram-positive (Staphylococcus aureus ATCC 6538) bacteria were used to test the antimicrobial activity of the coated films. The strains were cultured in TSB (tryptic soy broth: peptone from casein $17.0 \mathrm{~g} \mathrm{~L}^{-1}$; peptone from soymeal $3.0 \mathrm{~g} \mathrm{~L}^{-1}$; D-(+)-glucose $2.5 \mathrm{~g} \mathrm{~L}^{-1}$; sodium chloride $5.0 \mathrm{~g}$ $\mathrm{L}^{-1}$; and dipotassium hydrogen phosphate $2.5 \mathrm{~g} \mathrm{~L}^{-1}$ ) and TSA (tryptic soy agar: peptone from casein $15.0 \mathrm{~g} \mathrm{~L}^{-1}$; peptone from soymeal 5.0 $\mathrm{g} \mathrm{L}^{-1}$; sodium chloride $5.0 \mathrm{~g} \mathrm{~L}^{-1}$; and agar-agar $15.0 \mathrm{~g} \mathrm{~L}^{-1}$ ) all from 


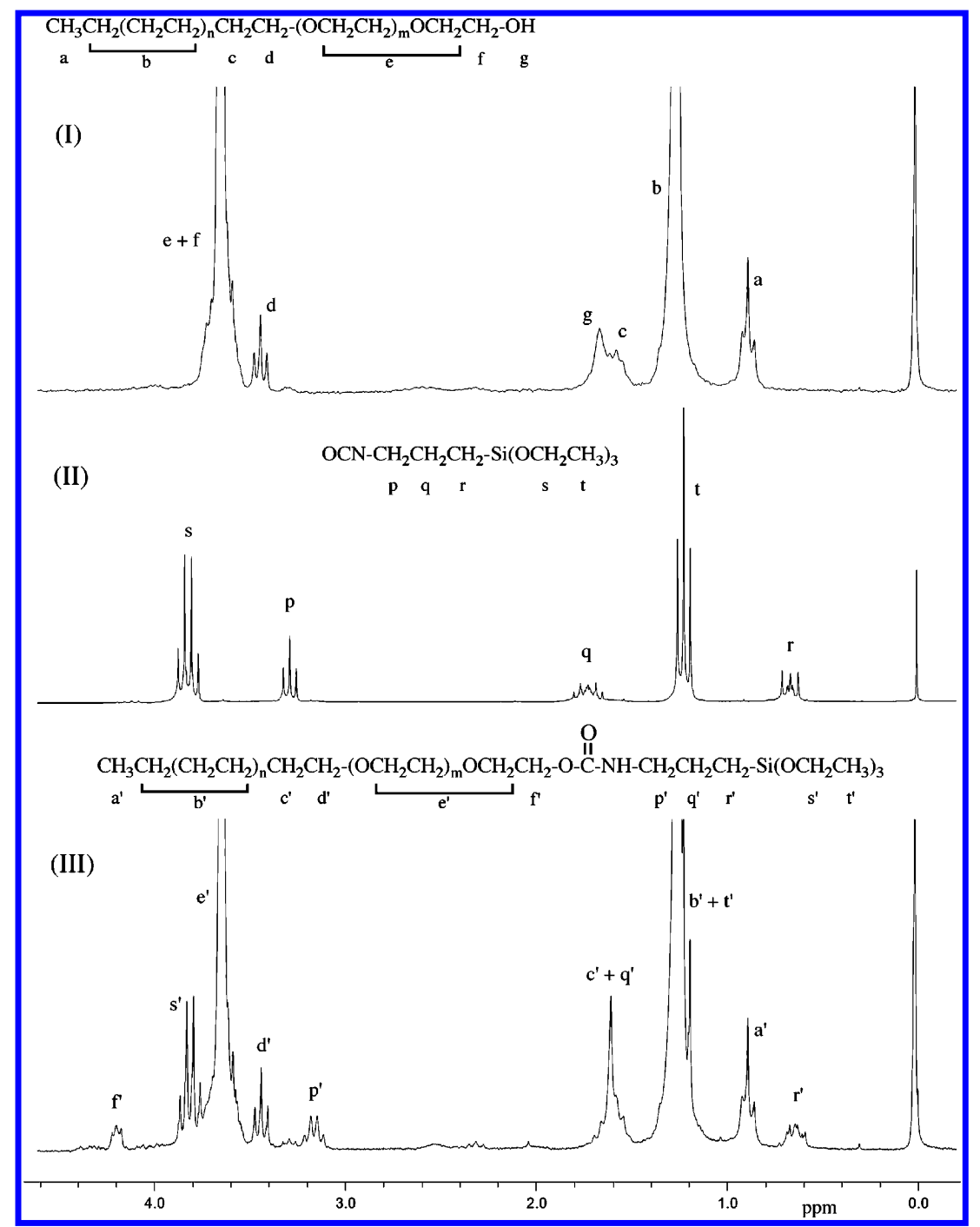

Figure 2. ${ }^{1} \mathrm{H}$ NMR spectra of hydroxyl-terminated PE-PEG (I), ICTES (II), and the derived product (PE-PEG-Si) after $3 \mathrm{~h}$ of reaction (III).

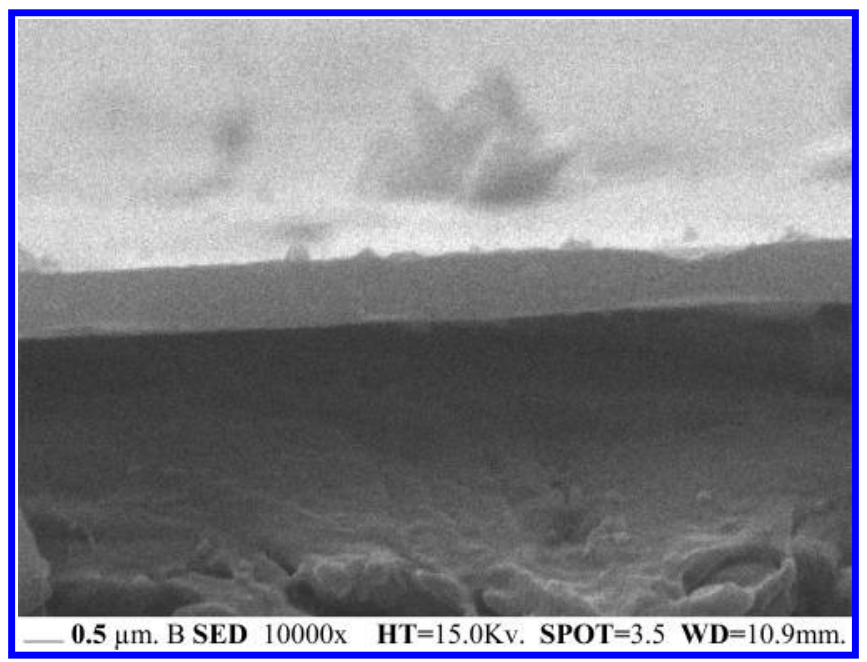

Figure 3. SEM edge view of a LDPE film with a PE-PEG-Si/SiO $(80: 20)$ coating. This picture is also representative for all the other coating-substrate systems.

Oxoid, S.p.A (Milan, Italy) with the appropriate times and temperatures of incubation $\left(37^{\circ} \mathrm{C}\right.$ for $\left.24-48 \mathrm{~h}\right)$.

2.2. Preparation of Triethoxysilane-Terminated Copolymers (PEPEG-Si). The reaction of PE-PEG copolymer with ICPTES ${ }^{44-47}$ was carried out in a $50 \mathrm{~mL}$ glass flask with magnetic stirring, at $120^{\circ} \mathrm{C}$, for $3 \mathrm{~h}$. ICPTES was directly added to the copolymers at a molar ratio
Table 1. Comparison of Antibacterial Activity of PE and PVC Polymer Substrates ${ }^{a}$

\begin{tabular}{|c|c|c|c|c|c|c|}
\hline & \multicolumn{3}{|c|}{ E. coli } & \multicolumn{3}{|c|}{ S. aureus } \\
\hline & $0 \mathrm{~h}$ & $6 \mathrm{~h}$ & $24 \mathrm{~h}$ & $0 \mathrm{~h}$ & $6 \mathrm{~h}$ & $24 \mathrm{~h}$ \\
\hline control & 100 & 70.3 & 70.3 & 100 & 68.4 & 68.4 \\
\hline $\begin{array}{c}\text { PE-coated PE-PEG-Si/ } / \mathrm{SiO}_{2} \\
(80: 20)+5 \% \mathrm{AgNO}_{3}\end{array}$ & 100 & 0 & 0 & 100 & 0.35 & 0 \\
\hline $\begin{array}{c}\text { PVC-coated PE-PEG-Si/SiO } \\
2 \\
(80: 20)+5 \% \mathrm{AgNO}_{3}\end{array}$ & 100 & 0 & 0 & 100 & 0.36 & 0 \\
\hline
\end{tabular}

${ }^{a}$ Results are expressed as percent residual bacterial concentration.

of 1.1:1. The progress of the reaction between hydroxyl groups of the copolymer and isocyanate groups of ICPTES was monitored by Fourier transform infrared (FT-IR) spectroscopy. It was found that, under the experimental conditions used in this study, the reaction was completed within $3 \mathrm{~h}$. The expected structure of the final product was confirmed by ${ }^{1} \mathrm{H}$ NMR

2.3. Preparation of PE-PEG-Si/Silica Hybrids. The triethoxysilaneterminated copolymer and TEOS were dissolved in tetrahydrofuran in the desired organic-inorganic ratios at a concentration of about $30 \%$ (w/v). Then water (for the hydrolysis reaction), EtOH (to make the system homogeneous), and $\mathrm{HNO}_{3}$ (acidic catalyst) were added at the following molar ratios with respect to ethoxide groups of functionalized copolymer and TEOS:EtO ${ }^{-}: \mathrm{H}_{2} \mathrm{O}: \mathrm{EtOH}: \mathrm{HNO}_{3}=1: 1: 1: 0.05$. Several samples with different concentrations of $\mathrm{AgNO}_{3}$ (0.5-5 wt \% with respect to the coating's weight) were added to the initial solutions before 
Table 2. Role of Organic-Inorganic Ratio and $\mathrm{Ag}^{+}$Concentration on Antibacterial Activitya

\begin{tabular}{|c|c|c|c|c|c|c|c|c|c|}
\hline \multirow{3}{*}{$\begin{array}{c}\text { PE-coated } \\
\text { PE-PEG-Si/SiO } 2 \text { ratio }\end{array}$} & \multirow[b]{3}{*}{$\% \mathrm{AgNO}_{3}$} & \multicolumn{4}{|c|}{ E. coli } & \multicolumn{4}{|c|}{ S. aureus } \\
\hline & & & & & & & & & \\
\hline & & $0 \mathrm{~h}$ & $6 \mathrm{~h}$ & $24 \mathrm{~h}$ & $72 \mathrm{~h}$ & $0 \mathrm{~h}$ & $6 \mathrm{~h}$ & $24 \mathrm{~h}$ & $72 \mathrm{~h}$ \\
\hline control & & 100 & 70.3 & 70.3 & 70.3 & 100 & 68.4 & 68.4 & 3.4 \\
\hline $80: 20$ & 2.5 & 100 & 0 & 0 & 0 & 100 & 1.62 & 0 & 0 \\
\hline $80: 20$ & 5 & 100 & 0 & 0 & 0 & 100 & 0.35 & 0 & 0 \\
\hline $50: 50$ & 2.5 & 100 & 0.41 & 0.02 & 0 & 100 & 11.3 & 0.04 & 0 \\
\hline $50: 50$ & 5 & 100 & 0.07 & 0 & 0 & 100 & 7.7 & 0 & 0 \\
\hline $20: 80$ & 2.5 & 100 & 1.58 & 0.41 & 0.025 & 100 & 22.8 & 0.07 & 0 \\
\hline $20: 80$ & 5 & 100 & 1.2 & 0.10 & 0 & 100 & 12.2 & 0.07 & 0 \\
\hline
\end{tabular}

${ }^{a}$ Results are expressed as percent residual bacterial concentration.

Table 3. Comparison of the Bactericide Effect of Different Counterions on the Antibacterial Activitya

\begin{tabular}{|c|c|c|c|c|c|c|c|c|}
\hline & \multicolumn{4}{|c|}{ E. coli } & \multicolumn{4}{|c|}{ S. aureus } \\
\hline & $\mathrm{Oh}$ & $6 \mathrm{~h}$ & $24 \mathrm{~h}$ & $72 \mathrm{~h}$ & $\mathrm{Oh}$ & $6 \mathrm{~h}$ & $24 \mathrm{~h}$ & $72 \mathrm{~h}$ \\
\hline control & 100 & 70.3 & 70.3 & 70.3 & 100 & 68.4 & 68.4 & 3.4 \\
\hline $\begin{array}{c}\text { PE-coated PE-PEG-Si/SiO } \\
(50: 50)+5 \% \mathrm{AgNO}_{3}\end{array}$ & 100 & 0.07 & 0 & 0 & 100 & 4.0 & 0 & 0 \\
\hline $\begin{array}{l}\text { PVC-coated PE-PEG-Si/SiO } 2 \\
\quad(50: 50)+5 \% \mathrm{AgCl}\end{array}$ & 100 & 0.23 & 0 & 0 & 100 & 4.3 & 0 & 0 \\
\hline
\end{tabular}

${ }^{a}$ Results are expressed as percent residual bacterial concentration.

Table 4. Comparison of Antibacterial Activity of $\mathrm{Ag}^{+}$and $\mathrm{Zn}^{2+}$ lons ${ }^{a}$

\begin{tabular}{lcccc}
\hline & \multicolumn{4}{c}{ E. coli } \\
\cline { 2 - 5 } & $0 \mathrm{~h}$ & $6 \mathrm{~h}$ & $24 \mathrm{~h}$ & $72 \mathrm{~h}$ \\
\hline $\begin{array}{l}\text { control } \\
\text { PE-coated PE-PEG-Si/SiO }\end{array}$ & 100 & 70.3 & 70.3 & 70.3 \\
$\quad(50: 50)+5 \% \mathrm{AgNO}_{3}$ & 100 & 0.07 & 0 & 0 \\
$\begin{array}{c}\text { PVC-coated PE-PEG-Si/SiO } \\
\quad\end{array}$ & 100 & 69.3 & 62.1 & 62.1 \\
$\quad(50: 50)+5 \% \mathrm{ZnCl}_{2}$ & & & & \\
\hline
\end{tabular}

${ }^{a}$ Results are expressed as percent residual bacterial concentration.

spin-coating. Basic catalysis, with either $\mathrm{NaOH}$ or ammonia, was also used to prepare hybrid coatings.

A typical preparation of PE-PEG-Si/SiO ${ }_{2}$ 50:50 (equal weight ratio between organic and inorganic phase if a complete reaction is assumed) was as follows: $0.70 \mathrm{~g}$ of PE-PEG-Si and $2.30 \mathrm{~g}$ of TEOS were added to $10 \mathrm{~mL}$ of tetrahydrofuran and mixed until a homogeneous solution was obtained. Then $2.92 \mathrm{~g}$ of a mixture of EtOH, water, and $\mathrm{HNO}_{3}$ (in molar ratio 1:1:0.05) was added under stirring, and then an appropriate amount of $\mathrm{AgNO}_{3}$ was added. The solution was then allowed to react at $60{ }^{\circ} \mathrm{C}$ for $2 \mathrm{~h}$ before application to the plastic substrate.

The final hybrids were coded as PE-PEG-Si/SiO $2 x: y$, in which $x: y$ is the organic to inorganic weight ratio component, where the occurrence of complete hydrolysis and condensation according to the reactions reported in Scheme 1 is assumed; hybrid coatings with 80:20, 50:50, and 20:80 organic-inorganic weight ratios were prepared.

2.4. Deposition of PE-PEG/Silica Hybrids onto Plastics Substrates. A model WS-400B-6NPP/LITE/8K spin coater was used for the deposition of solutions on PE and PVC films. Ag-doped PE-PEG$\mathrm{Si} / \mathrm{SiO}_{2}$ sol-gel solutions, prepared according to the procedure described above, were applied onto PE or PVC films $\left(130 \times 130 \mathrm{~mm}^{2}\right)$ by spin-coating at $1000 \mathrm{rpm}$ for $30 \mathrm{~s}$. The samples, after deposition, were typically subjected to a thermal post-treatment curing at $60{ }^{\circ} \mathrm{C}$ for $24 \mathrm{~h}$, although different postcuring times were also used for some samples. Another set of coated PE and PVC films, not doped with silver salts, were prepared with the same organic-inorganic composition and under the same reaction conditions, and were used as control samples.
2.5. Sample Characterization. The reaction of PE-PEG with ICPTES was followed by FT-IR analysis (Avatar 330 FT-IR Thermo Nicolet spectrometer with a ZnSe crystal). A minimum of 32 scans with a resolution of $2 \mathrm{~cm}^{-1}$ was used. Samples were analyzed by deposition of thin liquid film on a $\mathrm{ZnSe}$ crystal and recorded in attenuated total reflection (ATR) mode. ATR corrections were performed with the EZ-OMNIC software.

${ }^{1} \mathrm{H}$ NMR analysis of the product resulting from the reaction of PEPEG block copolymer with ICPTES was performed with a Bruker FTNMR DPX200 system $200 \mathrm{MHz}$ instrument by use of $\mathrm{CDCl}_{3}$ as solvent and tetramethylsilane as an internal reference.

Fracture surfaces of coated specimens were cut by a cryomicrotome and gold-coated before investigation by scanning electron microscopy (SEM) on a Philips XL-30 instrument.

2.6. Antibacterial Activity Evaluation. The antibacterial activity of the coatings against Escherichia coli ATCC 25922 and Staphylococcus aureus ATCC 6538 was determined by two different methods: (i) qualitative evaluation with a modified agar diffusion assay and (ii) quantitative evaluation in a liquid medium.

For the qualitative evaluation, coated and uncoated plastic films $(2 \times 2 \mathrm{~cm})$ were placed onto TSA plates and covered with $5 \mathrm{~mL}$ of tryptic soy soft agar (agar-agar $7.5 \mathrm{~g}^{-1}$ ) seeded with $10^{6} \mathrm{cfu} \mathrm{mL}^{-1}$ from overnight cultures of $E$. coli ATCC 25922 and $S$. aureus ATCC 6538. The plates were incubated at $37^{\circ} \mathrm{C}$ for $24 \mathrm{~h}$, and the antagonistic activity was identified and estimated by a clear zone of inhibition in the indicator lawn around the coated plastic films. Uncoated films were also tested as negative controls.

In order to quantitatively evaluate the antibacterial activity, samples of coated films were added in saline solution $(\mathrm{NaCl} 0.85 \mathrm{wt} \%$ in water) suspensions of E. coli ATCC 25922 and S. aureus ATCC $6538\left(10^{6}\right.$ cfu $\mathrm{mL}^{-1}$ ). The suspensions were incubated at $37^{\circ} \mathrm{C}$ with continuous shaking and, at regular intervals $(0,6,24$, and $72 \mathrm{~h})$, bacterial counts were determined by spreading on TSA plates. Uncoated films were included as negative controls.

The permanence of the antibacterial activity was investigated with the same methods (qualitative and quantitative evaluation) either after immersing samples in hot water $\left(50^{\circ} \mathrm{C}\right)$ or after a prolonged immersion (3 days) of the coated films in physiological saline solution at $37^{\circ} \mathrm{C}$.

2.7. Silver Ion Release Rate. The concentration of silver ions released in a physiological saline solution from the coated films was measured by inductively coupled plasma atomic emission spectroscopy 


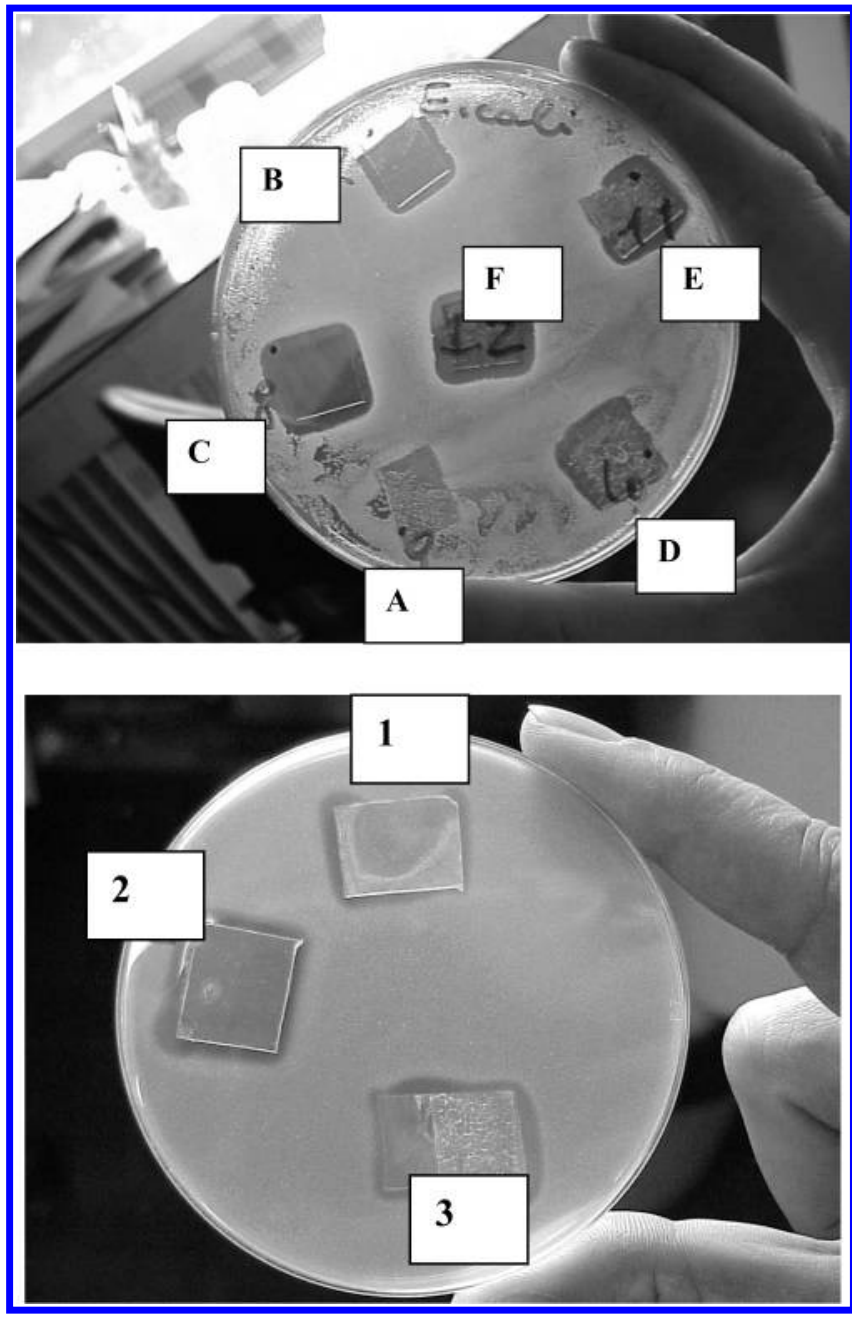

Figure 4. (Top panel) Qualitative antibacterial evaluation and examples of contact tests on E. coli: (A) control; (B) PE-PEG-Si/ $\mathrm{SiO}_{2}(80: 20)+1 \% \mathrm{AgNO}_{3}$; (C) PE-PEG-Si/SiO $2(80: 20)+2.5 \%$ $\mathrm{AgNO}_{3}$; (D) PE-PEG-Si/SiO 2 (50:50) + 2.5\% $\mathrm{AgNO}_{3}$; (E) PE-PEG$\mathrm{Si} / \mathrm{SiO}_{2}(50: 50)+5 \% \mathrm{AgNO}_{3} ;(\mathrm{F}) \mathrm{PE}-\mathrm{PEG}-\mathrm{Si} / \mathrm{SiO}_{2}(80: 20)+5 \%$ $\mathrm{AgNO}_{3}$. (Bottom panel) Qualitative antibacterial evaluation and examples of contact tests on S. aureus: (1) PE-PEG-Si/SiO 2 (50: $50)+1 \% \mathrm{AgNO}_{3}$; (2) PE-PEG-Si/SiO $2(80: 20)+1 \% \mathrm{AgNO}_{3}$; (3) PE$\mathrm{PEG}-\mathrm{Si} / \mathrm{SiO}_{2}(20: 80)+1 \% \mathrm{AgNO}_{3}$.

(ICP/AES). Various films (for an overall coated surface of $320 \mathrm{~cm}^{2}$, corresponding to about $38.4 \mathrm{mg}$ of PE-PEG-Si/SiO $\mathrm{S}_{2}$ (50:50) with $5 \%$ $\mathrm{AgNO}_{3}$ coating, containing $1.15 \mathrm{mg}$ of $\mathrm{Ag}^{+}$) were immersed in a physiological saline solution $(100 \mathrm{~mL})$ at $37^{\circ} \mathrm{C}$; the liquids recovered at various times (up to $48 \mathrm{~h}$ ) were concentrated to $5 \mathrm{~mL}$ in a rotary evaporator and analyzed by ICP/AES. A commercial ICP multistandard solution containing $50 \pm 0.1 \mathrm{ppm}$ of $\mathrm{Ag}^{+}$was used for calibration.

\section{Results and Discussion}

3.1. Preparation of Triethoxysilane-Terminated Copolymers. The commercial monohydroxyl-terminated PE-PEG block copolymer was reacted with ICPTES in order to have trialkoxysilane terminal groups able to react with TEOS faster than hydroxyl terminal groups and therefore to lead to a better interconnection with the inorganic phase in the coating. ${ }^{48,49}$ The progress of the reaction between hydroxyl-terminated PE-PEG copolymer and ICPTES was monitored by FT-IR spectroscopy by following the increase of the strong absorption band of the carbonyl of the urethane groups (at about $1700 \mathrm{~cm}^{-1}$ ) and the disappearance of the band related to isocyanate groups (at 2270 $\mathrm{cm}^{-1}$ ). Typical FT-IR spectra recorded at different reaction times

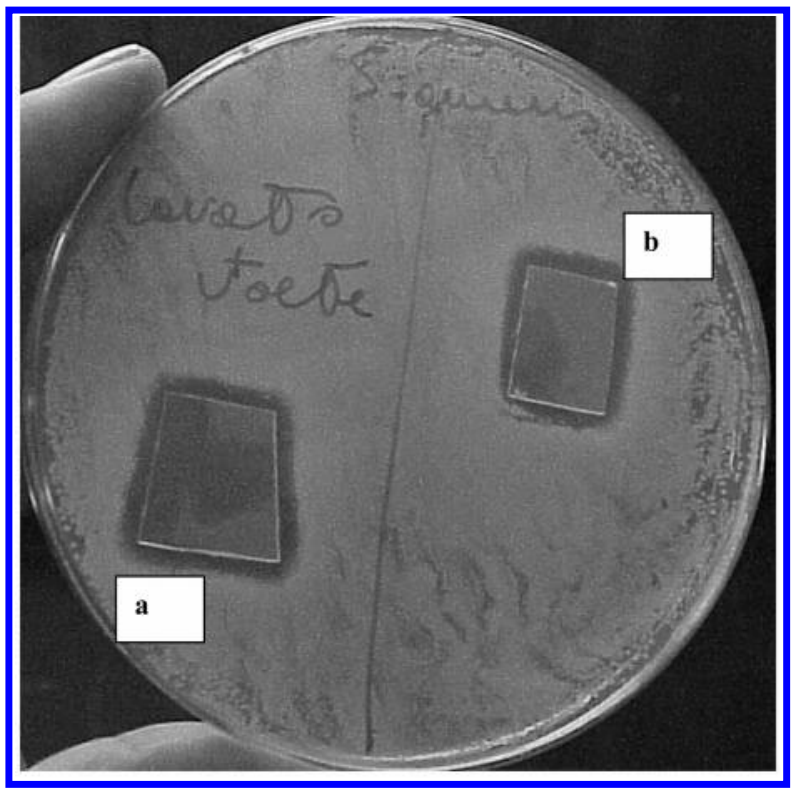

Figure 5. Antibacterial activity of $\mathrm{PE}$ film coated by $\mathrm{PE}-\mathrm{PEG}-\mathrm{Si} / \mathrm{SiO}_{2}$ $(50: 50)+5 \% \mathrm{AgNO}_{3}$ (a) washed 10 times in warm water at $50{ }^{\circ} \mathrm{C}$ and (b) not washed.

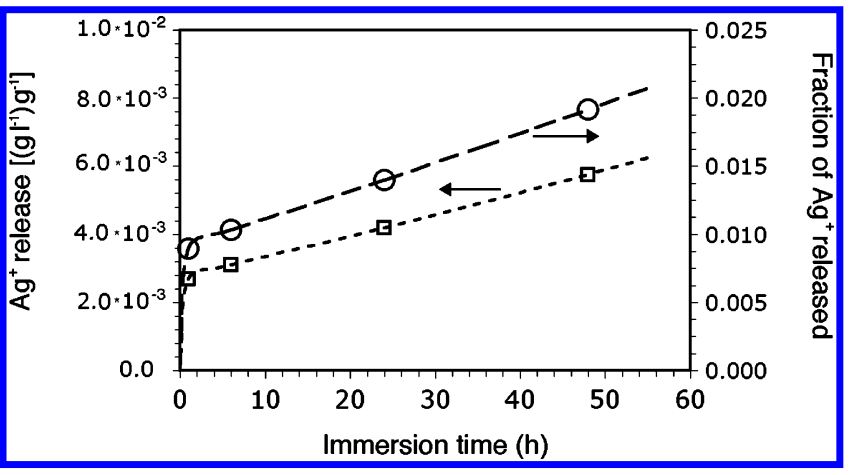

Figure 6. Silver ion release from a PE film coated with a PE-PEG$\mathrm{Si} / \mathrm{SiO}_{2}$ (50:50) hybrid coating $+5 \% \mathrm{AgNO}_{3}$ (coating thickness $0.8 \mu \mathrm{m})$ versus immersion time in a physiological saline solution at $37^{\circ} \mathrm{C}$ : ( $\square$ ) concentration released in $100 \mathrm{~mL}$ from $1 \mathrm{~g}$ of coating; $(\bigcirc)$ fraction of $\mathrm{Ag}^{+}$released.

are reported in Figure 1. The expected molecular structure was also confirmed by ${ }^{1} \mathrm{H}$ NMR analysis, and typical spectra of PEPEG copolymer, ICPTES, and PE-PEG-Si functionalized copolymer are reported in Figure 2 with the relative signal assignments. The spectrum of the final reaction product (III) showed the presence of signals attributable to both reactants and some peaks attributable to the reaction of hydroxylterminated PE-PEG with isocyanate groups of ICPTES. According to the literature, ${ }^{44-47,50}$ a clear indication that the two reactants are linked together is the formation of the peak at 4.25 ppm (spectrum III, signal $f^{\prime}$ ), attributable to hydrogens of methylene moieties adjacent to urethane groups. Further evidence of the occurrence of the expected reaction is the presence of a signal at $3.15 \mathrm{ppm}$ (spectrum III, signal p') attributable to methylene moieties linked to the nitrogen of the urethane group, which derives from the shifting of the peak present at $3.30 \mathrm{ppm}$ in unreacted ICPTES (spectrum II, signal p) related to methylene moieties adjacent to isocyanate groups. The ratios between signals of the reaction product were in good agreement with the chemical structure expected for the complete reaction of hydroxyl terminal groups of PE-PEG with the isocyanate groups of ICPTES, and therefore possible side reactions of the hydroxyl terminal group of PE-PEG with the alkoxy groups of ICPTES can be ignored. ${ }^{50}$ 
3.2. Coating Preparation and Application to Polymeric Substrates. The classical sol-gel process ${ }^{51}$ occurs by a twostep reaction mechanism including either acid- or base-catalyzed reactions of metal alkoxides $\mathrm{M}(\mathrm{OR})_{x}$, typically tetraethoxysilane (TEOS). Even though the reaction mechanism may be quite complex and until now not completely understood, several reactions can occur, involving metal-alkoxide hydrolysis and formation of intermediate species of the metal hydroxide type. These species then undergo a stepwise polycondensation involving both hydroxyl and alkoxy groups with the formation of linear and branched chains or particles and finally a metal oxide threedimensional network (see Scheme 1). The sol-gel process has proved to be flexible enough for an efficient incorporation of organic oligomers or polymers, and this approach is particularly interesting for polymers/oligomers bearing reactive groups that can be involved in the hydrolysis-condensation reactions so that polymer chains can be covalently bonded to silica domains. ${ }^{48,49}$

Typically the resulting networks contain residual unreacted silanol groups $(\mathrm{Si}-\mathrm{OH})$ in addition to siloxane bridges $(\mathrm{Si}-$ $\mathrm{O}-\mathrm{Si}$ ), whose concentration (silicon average connectivity) depends on the reaction conditions used to prepare the coating. It is also important to emphasize that the final morphology depends on the relative rates of various phenomena (reactions, phase separation, solvent evaporation, etc.) and different morphologies are expected from different process conditions. In particular, different reaction rates of siloxane chain growth and of particle formation are predicted for acidic and basic catalysts. ${ }^{52-55}$ Linear and branched siloxane chains grow preferably under acidic conditions before forming a final network, whereas under basic catalysis particles grow first and then link themselves to form a three-dimensional network of particles in the final part of the process.

In this study the triethoxysilane-terminated copolymer was mixed with TEOS, solvent, catalyst, water, and inorganic salts to form a homogeneous solution, which was allowed to react at $60{ }^{\circ} \mathrm{C}$ for $2 \mathrm{~h}$ before application to the plastic substrates. Many variables can affect the antibacterial activity, and in order to investigate their effects on the antibacterial properties of the coated films some of these have been considered and varied during the preparation of the coatings, namely, type of substrate (PE or PVC); organic-inorganic ratio $(80: 20,50: 50$, or 20 : 80); postcuring time at $60{ }^{\circ} \mathrm{C}$ after deposition (12, 24, or $48 \mathrm{~h}$ ); type of inorganic salt; concentration of silver salts with respect to the weight of the hybrid coating $(0.5,1,2.5$, or $5 \mathrm{wt} \%)$; type of counterions $\left(\mathrm{NO}_{3}{ }^{-}\right.$or $\mathrm{Cl}^{-}$); and type of catalysis (acidic, $\mathrm{HNO}_{3}$, or basic, ammonia and $\mathrm{NaOH}$ ).

Other variables, like concentration of reactants in the solvent $(30 \% \mathrm{w} / \mathrm{v})$, time of precuring of the solution before application to the plastic films $\left(2 \mathrm{~h}\right.$ at $\left.60^{\circ} \mathrm{C}\right)$, spin rate during application (1000 rpm), rotational acceleration (0.10), and time of rotation (30 s), were maintained constant.

After curing, all the coatings were optically transparent (unchanged with respect to that of the initial uncoated films) and showed good adhesion to the substrate on visual inspection. The very good transparency of the coatings can be attributed to the nanosizes of the organic and inorganic domains in the coatings.

Scanning electron microscopy was used to investigate some morphological aspects of the surface, to evaluate the thickness of the coating (from the edge view of film samples) and to get further detail about the adhesion of the coating to the plastic substrate. The surfaces of all the samples were free from cracks, holes, and any other significant defects. The thickness of the coatings, estimated from the cross-sectional view of the SEM pictures, slightly increased when the organic/inorganic ratio increased, ranging from $0.6 \mu \mathrm{m}$ for the 20:80 samples to 1.1 $\mu \mathrm{m}$ for the 80:20 organic-inorganic ratio. A typical edge view of a coated film cut by a cryomicrotome at $-20{ }^{\circ} \mathrm{C}$ is reported in Figure 3; as it appears the adhesion of the coating to the substrate is quite good. This qualitative information is supported by semiquantitative scratch-test experiments. ${ }^{47}$

3.3. Antibacterial Activity Evaluation. Qualitative and quantitative evaluations of the antibacterial activity were carried on many different coated films. Figure 4 shows typical results of the tests carried out for the purpose of a first qualitative evaluation; the antibacterial activity is evidenced by a zone of bacteria-growth inhibition, $2-3 \mathrm{~mm}$ wide, around the coated plastic samples. A similar inhibition zone is not present around the uncoated film (sample A in Figure 4, top panel), and there is bacteria growth also on the top part of the sample. As expected, the most notable antibacterial effect is observed for the coatings with the highest $\mathrm{Ag}^{+}$salt concentration (at 2.5 and 5 wt \%, in samples C, D and E, F in Figure 4, top panel, respectively); a reduced antibacterial effect is noted at $1 \mathrm{wt} \%$ concentration (sample B, in Figure 4, top panel).

Figure 4, bottom panel, shows the effect of the organicinorganic ratio; the best antibacterial activity is obtained for the hybrid samples richest in organic phase, namely, for sample characterized by the $80: 20$ organic-inorganic ratio (sample 2).

On the basis of these results, quantitative tests were carried out on films with coatings containing 2.5 or $5 \mathrm{wt} \%$ silver nitrate and with different organic-inorganic ratios.

Tables 1-4 show data from the quantitative antibacterial activity evaluation; as it appears from Table 1 , after $6 \mathrm{~h}$ of exposure the viable count for $E$. coli showed an almost complete disappearance for both PE and PVC coated substrates (more than $6 \log$ reduction), while under the same conditions the control solution showed a decrease of only $29.7 \%$. Similar results were observed for S. aureus; a marked decrease $(99.7 \%$ ) was observed after $6 \mathrm{~h}$, while under the same conditions the control solution showed a decrease of only $31 \%$. The strain disappeared completely (more than $6 \log$ reduction) after $24 \mathrm{~h}$ for both bacteria and substrates.

Some tests were also performed on PE and PVC films coated with hybrid coatings having the same composition but not doped with silver salts. The antibacterial activity observed for these samples was almost the same as for uncoated films, and it can be concluded that the antagonism is due to the $\mathrm{Ag}$ salt used to dope the coatings, and it is influenced neither by the type of substrate nor by the undoped coating.

The effect of different organic/inorganic ratios in the coatings is reported in Table 2 . When the antibacterial activity was tested against $E$. coli, all coatings tested showed a marked decrease even after $6 \mathrm{~h}$, with just a slight decrease of the antibacterial effect when the organic/inorganic ratio was decreased (from $80: 20$ to 20:80). A high level of antibacterial action was observed also for S. aureus; however, a significant decrease of the antibacterial effect was noted in this case for the coatings containing high contents of inorganic phase. As expected, the antibacterial effect increases with the amount of silver salt, and the highest antibacterial effect was obtained for samples with an organic-inorganic ratio of 80:20 and 5\% (w/w) silver nitrate.

The effects of both organic/inorganic ratio and $\mathrm{Ag}^{+}$salt concentration suggest that the antibacterial activity is diffusioncontrolled and that diffusion occurs, mainly or completely, through the organic phase. A higher content of inorganic phase 
Table 5. Antibacterial Activity Loss Data before (First Test) and after (Second Test) Immersiona

\begin{tabular}{|c|c|c|c|c|c|c|c|c|c|}
\hline \multirow[b]{2}{*}{ PE-coated } & \multirow[b]{3}{*}{$\% \mathrm{AgNO}_{3}$} & \multicolumn{4}{|c|}{ E. coli (1st test) } & \multicolumn{4}{|c|}{ E. coli (2nd test) } \\
\hline & & & & & & & & & \\
\hline PE-PEG-Si/SiO ${ }_{2}$ ratio & & $0 \mathrm{~h}$ & $6 \mathrm{~h}$ & $24 \mathrm{~h}$ & $72 \mathrm{~h}$ & $\mathrm{Oh}$ & $6 \mathrm{~h}$ & $24 \mathrm{~h}$ & $72 \mathrm{~h}$ \\
\hline control & & 100 & 70.3 & 70.3 & 70.3 & 100 & 70.3 & 70.3 & 70.3 \\
\hline $80: 20$ & 2.5 & 100 & 0 & 0 & 0 & 100 & 0 & 0 & 0 \\
\hline $80: 20$ & 5 & 100 & 0 & 0 & 0 & 100 & 0 & 0 & 0 \\
\hline $50: 50$ & 2.5 & 100 & 0.41 & 0.02 & 0 & 100 & 0.44 & 0.02 & 0.01 \\
\hline $50: 50$ & 5 & 100 & 0 & 0 & 0 & 100 & 0.07 & 0 & 0 \\
\hline $20: 80$ & 2.5 & 100 & 1.58 & 0.41 & 0.025 & 100 & 1.70 & 0.44 & 0.025 \\
\hline \multirow[t]{2}{*}{$20: 80$} & 5 & 100 & 1.2 & 0.10 & 0 & 100 & 1.6 & 0.20 & 0.01 \\
\hline & & \multicolumn{4}{|c|}{ S. aureus (1st test) } & \multicolumn{4}{|c|}{ S. aureus (2nd test) } \\
\hline \multicolumn{10}{|l|}{ PE-coated } \\
\hline PE-PEG-Si/SiO 2 ratio & $\% \mathrm{AgNO}_{3}$ & $\mathrm{Oh}$ & $6 \mathrm{~h}$ & $24 \mathrm{~h}$ & $72 \mathrm{~h}$ & $\mathrm{Oh}$ & $6 \mathrm{~h}$ & $24 \mathrm{~h}$ & $72 \mathrm{~h}$ \\
\hline control & & 100 & 68.4 & 68.4 & 3.4 & 100 & 68.4 & 68.4 & 3.4 \\
\hline $80: 20$ & 2.5 & 100 & 1.62 & 0 & 0 & 100 & 1.64 & 0 & 0 \\
\hline $80: 20$ & 5 & 100 & 0.35 & 0 & 0 & 100 & 0.36 & 0.14 & 0 \\
\hline $50: 50$ & 2.5 & 100 & 11.3 & 0.04 & 0 & 100 & 15.6 & 0 & 0 \\
\hline $50: 50$ & 5 & 100 & 7.7 & 0 & 0 & 100 & 9.3 & 0 & 0 \\
\hline $20: 80$ & 2.5 & 100 & 22.8 & 0.07 & 0 & 100 & 25.4 & 0 & 0 \\
\hline $20: 80$ & 5 & 100 & 12.2 & 0.07 & 0 & 100 & 13.8 & 0 & 0 \\
\hline
\end{tabular}

${ }^{a}$ Immersion took place in a physiological saline solution at $37^{\circ} \mathrm{C}$ for 3 days. Results are expressed as percent residual bacterial concentration.

leads to a higher volume of highly cross-linked inorganic domains and to a higher content of silanol groups $(\mathrm{Si}-\mathrm{OH})$ within the coating (typically $20 \mathrm{~mol} \%$ of silanol groups remain unreacted under the reaction condition used $^{56}$ ). Both these parameters are expected to reduce the $\mathrm{Ag}^{+}$diffusion rate as a smaller volume fraction of the organic domains leads to a higher tortuosity and to a reduced chain mobility of the PE-PEG chains, which are confined in smaller domains, are more strongly entangled with the inorganic network, and interact more extensively with silanol groups via hydrogen bonding. All these factors may contribute to a decrease of the diffusivity of $\mathrm{Ag}^{+}$ ions within the coating and can explain the observed decrease of antibacterial activity when the inorganic/organic ratio is increased.

In principle, the counterion mobility could also affect the $\mathrm{Ag}^{+}$ ions' mobility, and therefore the antibacterial activity was tested for coatings containing Ag salts with different counterions. The results reported in Table 3 show that the antibacterial activity was the same for both $E$. coli and $S$. aureus when $\mathrm{Cl}^{-}$or $\mathrm{NO}_{3}{ }^{-}$ was used, suggesting that the counterion contribution to the antibacterial activity is negligible, if existing.

In the literature it was argued that also $\mathrm{Zn}^{2+}$ ions are able to have an antibacterial effect; ${ }^{18}$ therefore, coatings containing $\mathrm{ZnCl}_{2}$ were also prepared and tested against E. coli and $S$. aureus. As shown in Table 4, the coated films containing $\mathrm{ZnCl}_{2}$ were proved not to have any significant antibacterial effect, suggesting that the interaction of the $\mathrm{Zn}^{2+}$ ions with the coating medium is stronger than that of the $\mathrm{Ag}^{+}$ions and does not allow a sufficiently fast diffusion rate of these ions to the surface.

Also, changes in the postcuring time (carried out in a traditional oven at $60{ }^{\circ} \mathrm{C}$ for 12,24 , and $48 \mathrm{~h}$ ) did not seem to have any effect on the antibacterial properties. Considering that an increase of postcuring time should increase the extent of reaction, and therefore the cross-linking density within the inorganic-phase domains, it can be concluded that the connectivity of the inorganic network within the inorganic domains can be ruled out as an important factor in the control of the antibacterial activity; this is a further support to the conclusion that the $\mathrm{Ag}^{+}$ions move preferably within the organic-phase domains.

3.4. Permanence of the Antibacterial Activity. Another important property that may be required for use with antibacterial plastics in many applications is the permanence of the antibacterial activity over time and/or after immersion in aqueous environments. A steady and prolonged release of silver ions at a suitable concentration level $(>0.1 \mathrm{ppb})^{57}$ is required in order to have an effective and "permanent" biocidal activity; a tooslow or a too-fast release of $\mathrm{Ag}^{+}$would be unsuitable for most applications.

The diffusion rate of $\mathrm{Ag}^{+}$ions within a hybrid coating is expected to depend on several variables, namely, the concentration of the $\mathrm{Ag}^{+}$within the coating, the amount and chemical nature of the organic phase, and in particular, the molecular architecture and morphology of the nanocomposite hybrid coating resulting from the sol-gel process. The residual hydroxyl groups within the coating (silanol groups), ${ }^{58}$ and the water uptake capability, ${ }^{25,57}$ strictly related to the above cited factors, may also play an important role on the rate of $\mathrm{Ag}^{+}$ release. A good balance of all the parameters involved in the control of these coating features is required to obtain a longterm release of $\mathrm{Ag}^{+}$ions in biocidal concentration.

Various experiments were carried out to investigate this point. A first investigation was carried out by repeating qualitative and quantitative tests either on samples that have been previously washed at least 10 times in warm water (at $50^{\circ} \mathrm{C}$ ) or on samples immersed in a physiological saline solution at $37^{\circ} \mathrm{C}$ for a long time (3 days). Figure 5 and Table 5 show data for coatings prepared under acidic catalysis, tested after washing in warm water and immersion in physiological saline solution, respectively. As it appears in Figure 5, qualitative contact tests on coated plastics show the same antibacterial activity before (b) and after (a) washes with warm water.

The data reported in Table 5 confirm that there is no difference between the first and the second test (after 3 days of 
Table 6. Silver Ion Release from a PE Film versus Immersion Time $^{a}$

\begin{tabular}{ccccc}
\hline & $\begin{array}{c}\text { amount } \\
\text { of } \mathrm{Ag}^{+} \\
\text {released } \\
\text { immersion } \\
\text { time }(\mathrm{h})\end{array}$ & $\begin{array}{c}\mathrm{g}) \\
\text { fraction of }_{\mathrm{Ag}^{+} \text {released }}\end{array}$ & $\begin{array}{c}\text { concn of } \\
\mathrm{Ag}^{+}\left(\mathrm{g} \mathrm{L}^{-1}\right) \\
\left.\text { for } 1 \mathrm{~g}^{-1}\right) \\
\text { coating }^{d}\end{array}$ & $\begin{array}{c}\text { concn of } \\
\mathrm{Ag}^{+}\left(\mathrm{g} \mathrm{L}^{-1}\right) \\
\text { for } 1 \mathrm{~cm}^{2} \text { of } \\
\text { coating }^{e}\end{array}$ \\
\hline 0 & 0 & 0 & 0 & 0 \\
1 & $1.03 \times 10^{-5}$ & 0.0089 & $2.7 \times 10^{-3}$ & $3.2 \times 10^{-7}$ \\
6 & $1.19 \times 10^{-5}$ & 0.0103 & $3.1 \times 10^{-3}$ & $3.7 \times 10^{-7}$ \\
24 & $1.61 \times 10^{-5}$ & 0.0140 & $4.2 \times 10^{-3}$ & $5.0 \times 10^{-7}$ \\
48 & $2.20 \times 10^{-5}$ & 0.0191 & $5.7 \times 10^{-3}$ & $6.9 \times 10^{-7}$
\end{tabular}

a The PE film had a PE-PEG-Si/SiO 2 (50:50) hybrid coating with $5 \%$ $\mathrm{AgNO}_{3}$ (coating thickness $0.8 \mu \mathrm{m}$ ). Immersion took place in a physiological saline solution at $37^{\circ} \mathrm{C}$. ${ }^{b}$ From $38.4 \mathrm{mg}$ of coating immersed in $100 \mathrm{~mL}$ of solution. ${ }^{c}$ With respect to the total amount of $\mathrm{Ag}^{+}$in the coating (1.15 $\mathrm{mg}){ }^{d}$ Released in $100 \mathrm{~mL}$ of solution from $1 \mathrm{~g}$ of coating. ${ }^{e}$ Released from $1 \mathrm{~cm}^{2}$ of coating (a coating density $\approx 1.5 \mathrm{~g} \mathrm{~cm}^{-3}$ is assumed).

immersion) for both $E$. coli and $S$. aureus; actually, for $S$. aureus there is a small loss of antibacterial activity in the second test (less than 3\%) for all samples after $6 \mathrm{~h}$, but no difference was found after $24 \mathrm{~h}$

In order to confirm that these coatings are able to give a prolonged release of $\mathrm{Ag}^{+}$in biocidal concentration, the $\mathrm{Ag}^{+}$ concentration released from 50:50 organic-inorganic doped coatings to a physiological saline solutions was measured at various times (up to $48 \mathrm{~h}$ ) by ICP/AES. Data are reported in Figure 6 and Table 6. As it appears the $\mathrm{Ag}^{+}$reaches a concentration of about $0.1 \mathrm{ppm}\left(1 \times 10^{-5} \mathrm{~g}\right.$ in $100 \mathrm{~mL}$, well above that required for biocidal efficiency) in a short time (within $1 \mathrm{~h}$ ), due probably to the release of the $\mathrm{Ag}^{+}$present very close to the surface, and then it increases linearly within $48 \mathrm{~h}$ at a release rate of about $5 \times 10^{-6} \mathrm{~g}$ per day $(0.5 \%$ of the overall $\mathrm{Ag}^{+}$in the coating, $\mathrm{O}$ in Figure 6)

It is interesting to compare these data with those recently reported in the scientific literature about $\mathrm{Ag}^{+}$release from a polyamide (PA, copolyamide $6 / 6,6$, density $1.12 \mathrm{~g} \mathrm{~cm}^{-3}$ ) filled with different kinds of Ag-containing additives, including metallic silver nanoparticles. ${ }^{24,25}$

When the concentration of $\mathrm{Ag}^{+}$released in $100 \mathrm{~mL}$ of physiological saline solution by $1 \mathrm{~g}$ of coating, containing about $3 \mathrm{wt} \% \mathrm{Ag}^{+}$(see Figure 6 and Table 6), is compared with that released by $1 \mathrm{~g}$ of PA filled with $4 \mathrm{wt} \%$ silver nanoparticles (Figure 5 in ref 24), it can be observed that the rate of release of $\mathrm{Ag}^{+}$from the coating is several orders of magnitude higher in the short term and about 500 times higher after 10 days.

On the other hand, if the comparison is made on the basis of the same surface in contact with the aqueous environment, the result is quite different. In fact, when the density of the filled PA (about $1.12 \mathrm{~g} \mathrm{~cm}^{-3}$ ) is taken into account, the surface of 1 $\mathrm{g}$ of PA composite $1 \mathrm{~mm}$ thick (as used in ref 24) in contact with the aqueous solution is about $18 \mathrm{~cm}^{2}$, and the concentration of $\mathrm{Ag}^{+}$released to $100 \mathrm{~mL}$ of aqueous solution after 10 days can be estimated to be about $2.5 \times 10^{-6}\left(\mathrm{~g} \mathrm{~L}^{-1}\right) \mathrm{cm}^{-2}$ from Figure 5 of ref 24. A similar calculation made for our coating, if it is assumed that the $\mathrm{Ag}^{+}$concentration increases with the same slope up to 10 days, leads to a value of about $2.0 \times 10^{-6}$ $\left(\mathrm{g} \mathrm{L}^{-1}\right) \mathrm{cm}^{-2}$, quite similar to that found for PA composites. This result seems to support the conclusion that the $\mathrm{Ag}^{+}$ions move within the organic phase of the coating with a diffusion mechanism similar to that operating for PA composites. On the other hand, due to the much higher specific surface of the coating, the same antibacterial activity observed for PA composite can be obtained with the coating approach by using a much smaller amount of silver, with significant benefits in terms of costs and environmental risks.
Table 7. Effect of the Catalyst Used in the Sol-Gel Process on the Antibacterial Activity Loss Data for $S$. aureus before (First Test) and after (Second Test) Washing ${ }^{a}$

\begin{tabular}{|c|c|c|c|c|c|c|}
\hline & \multicolumn{3}{|c|}{ S. aureus (1st test) } & \multicolumn{3}{|c|}{ S. aureus (2nd test) } \\
\hline & $0 \mathrm{~h}$ & $6 \mathrm{~h}$ & $24 \mathrm{~h}$ & $\mathrm{Oh}$ & $6 \mathrm{~h}$ & $24 \mathrm{~h}$ \\
\hline control & 100 & 68.4 & 68.4 & 100 & 68.4 & 68.4 \\
\hline $\begin{array}{l}\text { PE-coated } \\
\text { PE-PEG-Si/SiO } \\
(80: 20)+5 \% \mathrm{AgNO}_{3} \\
\text { acidic catalyst }\end{array}$ & 100 & 0.35 & 0 & 100 & 0.36 & 0.14 \\
\hline $\begin{array}{l}\text { PE-coated } \\
\text { PE-PEG-Si/SiO } \\
(80: 20)+5 \% \mathrm{AgNO}_{3} \\
\text { basic catalyst }\end{array}$ & 100 & 5.90 & 0 & 100 & 60.3 & 60.3 \\
\hline
\end{tabular}

a Washing was done with a physiological saline solution at $37^{\circ} \mathrm{C}$ Results are expressed as percent residual bacterial concentration.

Some further tests were carried out to investigate the effect of the final morphology on the release rate of $\mathrm{Ag}^{+}$. Contrary to what was observed for coating prepared under acidic catalysis, a strong difference between the first and the second test was observed when the coatings were prepared under basic catalysis. Table 7 shows the comparison of the antibacterial activity against $S$. aureus for PE-PEG-Si/SiO 2 (80:20) coating with 5\% $\mathrm{AgNO}_{3}$ obtained either by acidic or by basic catalysis. As it appears, the coating prepared by basic catalysis showed a good antibacterial activity level in the first test, but it behaved like the control undoped film in the second test, after being immersed in a physiological saline solution. It is known from the literature ${ }^{52-55}$ that the coating morphology is strongly dependent on the type of catalysis used, and in particular that less interpenetration of the organic and inorganic phases is expected under basic catalysis. The observed results can be explained by assuming that $\mathrm{Ag}^{+}$ions have a much higher mobility in the coating prepared by basic catalysis and therefore are almost completely removed after immersion so that they are not present in a significant concentration during the second test.

\section{Conclusion}

According to the results reported in this paper, it can be concluded that commercial PE and PVC plastics (and possibly others) can be transformed into antibacterial plastics with a high antibacterial activity against both Gram-negative (Escherichia coli ATCC 25922) and Gram-positive (Staphylococcus aureus ATCC 6538) bacteria when they are coated with silver-doped organic-inorganic hybrid materials, prepared by a sol-gel process.

The antibacterial activity of the coated films is related to the diffusion capability of $\mathrm{Ag}^{+}$ions within the organic phase of the coating and can be affected by several parameters, and in principle can be controlled to some extent by controlling the composition of the coating and the sol-gel process conditions. The best antibacterial activity was demonstrated by samples with coatings with an organic-inorganic ratio of 80:20 and 5 wt \% silver salt content with respect to the coating weight. Due to the different morphologies resulting under acidic or basic catalysis, the antibacterial activity was almost unaffected after several washes or after a long time of immersion when the coatings were prepared by acidic catalysis, whereas it disappears completely after the first wash for coatings prepared by basic catalysis. The good antibacterial activity observed for use over both a short and a long period of time, when the coating is in 
contact with aqueous solutions, suggests that this approach can be usefully exploited in various industrial applications.

A comparison of the $\mathrm{Ag}^{+}$release rate from the coating with that reported in the literature for semicrystalline PA filled with metallic silver nanoparticles shows that the release rate per surface unit is quite similar for the coating ( $0.8 \mu \mathrm{m}$ thick) and the PA specimen (1 mm thick); however, the amount of $\mathrm{Ag}$ required to have similar release rates is about 500 times higher in the case of PA composites $1 \mathrm{~mm}$ thick. This means that the coating approach can give benefits with respect to both costs and environmental risks.

In addition to the good antibacterial properties observed, the coated films showed the same transparency as the uncoated ones (due to the nanosized organic and inorganic domains) and quite good adhesion to both PE and PVC substrates, even without any preliminary treatment of the plastic film surfaces. These results along with the relative low cost of reactants and the easy application of the coatings to plastic substrates also of complex geometry suggest that a number of potential applications are possible, and in particular in the field of food packaging and biomedical devices.

Acknowledgment. This work was partially supported by PRRIITT (Regione Emilia Romagna), Net-Lab "Surface \& Coatings for Advanced Mechanics and Nanomechanics" (SUP\&RMAN). This work has been carried out in the frame of activities within EU NoE NANOFUN-POLY.

\section{References and Notes}

(1) Lee, S. B.; Koepsel, R. R.; Morley, S. W.; Matyjaszewski, K.; Sun, Y.; Russell, A. Y. Biomacromolecules 2004, 5, 877-882.

(2) Lin, J.; Qiu, S.; Lewis, K.; Klibanov, A. M. Biotechnol. Prog. 2002, $18,1082-1086$.

(3) Lin, J.; Tiller, J. C.; Lee, S. B.; Lewis K.; Klibanov, A. M. Biotechnol. Lett. 2002, 24, 801-805

(4) Dizman, B.; Elasri, M. O.; Mathias, L. J. Biomacromolecules 2005, $6,514-520$.

(5) Lin, J.; Murthy, S. K.; Olsen, B. D.; Gleason, K. K.; Klibanov, A. M. Biotechnol. Lett. 2003, 25, 1661-1665.

(6) Rabea, E. I.; Badawy, M. E. T.; Stevens, C. V.; Smagghe, G.; Steurbaut, W. Biomacromolecules 2003, 4, 1457-1465.

(7) Sarasam, A. R.; Krishnaswamy, R. K.; Madihally, S. V. Biomacromolecules 2006, 7 1131-1138.

(8) Lenoir, S.; Pagnoulle, C.; Galleni, M.; Compere, Ph.; Jerome, R.; Detrembleur, C. Biomacromolecules 2006, 7, 2291-2296.

(9) Dobmeier, K. P.; Schoenfish, M. H. Biomacromolecules 2004, 5, $2493-2495$.

(10) Nablo, B. J.; Chen, T. Y.; Schoenfish, M. H. J. Am. Chem. Soc. 2001, 123, 9712-9713.

(11) Marxer, S. M.; Rothrock, A. R.; Nablo, B. J.; Robbins, M. E.; Schoenfish, M. H. Chem. Mater. 2003, 15, 4193-4199.

(12) Abel, T.; Cohen, J. I.; Engel, R.; Filshtinskaya, M.; Melkonian, A.; Melkonian, K. Carbohvdr. Res. 2002, 337, 2495-2499.

(13) Chen, Y.; Worley, S. D.; Kim, J.; Wei, C. I.; Chen, T. Y.; Santiago J. I.; Williams J. F.; Sun, G. Ind. Eng. Chem. Res. 2003, 42, 280284.

(14) Tiller, J. C.; Liao, C. J.; Lewis, K; Klibanov, A. M. Proc. Natl. Acad. Sci. U.S.A. 2001, 98, 5981-5985.

(15) Tiller, J. C.; Lee, S. B.; Lewis, K.; Klibanov, A. M. Biotechnol. Bioeng. 2002, 79, 465-471.

(16) Lin, J.; Qiu, S.; Lewis, K.; Klibanov, A. M. Biotechnol. Bioeng. 2003, $83,168-172$.

(17) Grier, N. In Disinfection, sterilization and preservation, 3rd ed.; Block, S. S., Ed.; Lea \& Febiger: Philadelphia, PA, 1983; pp 375389 .

(18) Crescenzi, V.; Francescangeli, A. J. Bioact. Compat. Polvm. 2003, 18, 229-235.

(19) Burrell, R. E. Ostomv/Wound Manage. 2003, 49, 19-24.
(20) Feng, Q. L.; Wu, J.; Chen, G. Q.; Cui, F. Z.; Kim, T. N.; Kim, J. O. J. Biomed. Mater. Res. 2000, 52, 662-668.

(21) Berger, T. J.; Spadaro, J. A.; Chapin, S. E.; Becker, R. O. Antimicrob. Agents Chemother. 1976, 9, 357-358.

(22) Russell, A. D.; Hugo, W. B. Prog. Med. Chem. 1994, 31, 351-370.

(23) Taylor, P. L.; Ussher, A. L.; Burrell, R. E. Biomaterials 2005, 26, 7221-7229.

(24) Kumar, R; Munsted, H. Biomaterials 2005, 26, 2081-2088.

(25) Kumar, R; Howdle, S; Munsted, H. J. Biomed Mater. Res. 2005, $75 B, 311-319$.

(26) Sant, S. B.; Gill, K. S.; Burrell, R. E. $\underline{\text { Scr. Mater }}$ 1999, 41 (12), $1333-1339$.

(27) Sant, S. B.; Gill, K. S.; Burrell, R. E. Philos. Mag. Lett. 2000, 80, $249-256$.

(28) Sant, S. B.; Gill, K. S.; Burrell, R. E. Philos. Mag. A 2002, 82, 11151136.

(29) Gray, J. E.; Norton, P. R.; Marolda, C. L.; Valvano, M. A; Griffith, K. Biomaterials 2003, 24, 2759-2765.

(30) Bowling, D. P.; Donnelly K.; Connel, M. L.; Eloy, R.; Arnaud, M. N. Thin Solid Films 2001, 398, 602-606.

(31) Djokic, S. S.; Burrell, R. E.; Lee, N.; Field, D. J. Electrochem. Soc. 2001, 14, C191-C196.

(32) Fan, F. F.; Bard A. J. J. Phvs. Chem. B 2002, 106, 279-287.

(33) Wright, J. B.; Lam, K.; Hansen, D.; Burrell, R. E. Am. J. Infect. Control 1999, 27, 344-350.

(34) Saint, S.; Elmore, J. G.; Sullivan, S. D.; Emerson, S. S.; Koepsel, T. D. Am. J. Med. 1998, 105, 236-241.

(35) Dowling, D. P.; Betts, A. J.; Pope, C.; Mc Connell, M. L.; Eloy, R.; Arnaud, M. N. Surf. Coat. Technol. 2003, 16, 637-640.

(36) Klueh, U.; Wagner, V.; Kelly, S.; Johnson, A.; Bryers, J. D. J. Biomed. Mater. Res., Appl. Biomater. 2000, 53, 621-631.

(37) Dobmeier, K. P.; Schoenfish, M. H. Biomacromolecules 2004, 5 , 2493-2495.

(38) Nablo, B. J.; Chen, T. Y.; Schoenfish, M. H. J. Am. Chem. Soc. 2001, 123, 9712-9713.

(39) Marxer, S. M.; Rothrock, A. R.; Nablo, B. J.; Robbins, M. E.; Schoenfish, M. H.; Chem. Mater. 2003, 15, 4193-4199.

(40) Wang, Q.; Yu, H, Zhong, L.; Liu, J.; Sun, J.; Shen, J. Chem. Mater. 2006, 18, 1988-1994.

(41) Nablo, B. J.; Schoenfisch, M. H. Biomacromolecules 2004, 5, 20342041.

(42) Kawashita, M.; Tsuneyama, S.; Miyaji, F.; Kokubo, T.; Kozuka, H.; Yamamoto, K. Biomaterials 2000; 21, 393-398.

(43) Blees, M. H.; Winkelman, G. B.; Balkenende, A. R.; den Toonder, J. M. J. Thin Solid Films 2000, 359, 1-13.

(44) Messori, M.; Toselli, M.; Pilati, F.; Fabbri, E.; Fabbri, P.; Pasquali, L.; Nannarone, S. Polvmer 2004, 45, 805-813.

(45) Messori, M.; Toselli, M.; Pilati, F.; Fabbri, E.; Fabbri, P.; Fusoli, S.; Pasquali, L.; Nannarone, S. Polvmer 2003, 44, 4463-4470.

(46) Messori, M.; Toselli, M.; Pilati, F.; Mascia, L.; Tonelli, C. Eur. Polvm. J. 2002, 38, 1129-1136.

(47) Toselli, M.; Marini, M.; Fabbri, P.; Messori, M.; Pilati, F. J. Sol-Gel Sci. Technol. (in press).

(48) Tian, D.; Dubois, P.; Jerome, R. J. Polym. Sci., Polym. Chem. Ed. 1997, 35, 2295-2309.

(49) Tian, D.; Blancher, S.; Dubois, P.; Jerome, R. Polvmer 1998, 39, $855-864$.

(50) Kricheldorf, H. R.; Thiessen, H. H. Polvmer 2005, 46, 12103-12108.

(51) Sol-gel technology for thin films, fibers, preforms, electronics and speciality shapes; Klein, L. C., Eds: Noyes Publications, Park Ridge, NJ, 1988.

(52) Brinker, C. J.; Keefer, K. D.; Schaefer, D. W.; Ashley, C. S. J. NonCrvst. Solids 1982, 48, 47-64.

(53) Brinker C. J.; Keefer, K. D.; Schaefer, D. W.; Assink, R. A.; Kay, B. D.; Ashley, C. S. J. Non-Crust. Solids 1984, 63, 45-59.

(54) Brinker, C. J.; Tallant, D. R.; Roth, E. P.; Ashley, C. S. J. NonCrvst. Solids 1986, 82, 117-126.

(55) Scherer G. W. J. Non-Cryst. Solids 1985, 70, 301-322.

(56) Geppi, M.; et al. ${ }^{29} \mathrm{Si}-\mathrm{MAS} / \mathrm{NMR}$ investigation of hybrid coatings (manuscript in preparation).

(57) Wohrmann, R. M. J.; Munstedt, H. Infection 1998, 26, 49-52.

(58) Trevors, J. T. Water, Air. Soil Pollut. 1987, 34, 409-414.

BM060721B 